\title{
Impact of protein-rich meals on glycaemic response of rice
}

\author{
Rina Quek ${ }^{1}$, Xinyan $\mathrm{Bi}^{1}$ and Christiani Jeyakumar Henry ${ }^{1,2,3 *}$ \\ ${ }^{1}$ Clinical Nutrition Research Centre, Singapore Institute for Clinical Sciences, 14 Medical Drive, Singapore 117599, Singapore \\ ${ }^{2}$ Singapore Institute for Clinical Sciences, Agency for Science, Technology and Research (A*STAR), 30 Medical Drive, Singapore \\ 117609, Singapore \\ ${ }^{3}$ Department of Biochemistry, Yong Loo Lin School of Medicine, National University of Singapore, 8 Medical Drive, Singapore \\ 117596, Singapore
}

(Submitted 28 September 2015 - Final revision received 2 December 2015 - Accepted 15 December 2015 - First published online 9 February 2016)

\section{Abstract}

Asians typically consume carbohydrate-rich and high-glycaemic-index diets that have been associated with an increased risk of developing type 2 diabetes. Rice is rarely eaten alone such that it is of interest to investigate the effects of co-ingesting different protein-rich meals with rice on insulin and glycaemic response. This study had a randomised, controlled, non-blind, cross-over design in which fifteen healthy Chinese male participants were required to come on non-consecutive days. Five rice-based test meals were served: rice alone (control), rice with fish (RWF), rice with egg white (RWE), rice with soya beancurd (taukwa) (RWT) and rice with chicken (RWC). The control meal consisted of $50 \mathrm{~g}$ of available carbohydrate, whereas all other test meals contained additional $25 \mathrm{~g}$ of protein. RWT was the only meal that showed significantly lower glucose response when compared with the control $(P<0.05)$. RWF and RWE had significantly higher insulin response, but no significant increase was observed in RWT and RWC when compared with the control $(P<0 \cdot 05)$. RWT and RWF showed significantly higher glucagon secretion as compared with the control $(P<0 \cdot 05)$. The four test meals studied showed varying effects, with RWT showing the greatest reduction in glycaemic response. Therefore, the ingestion of soya beancurd with rice may have a direct impact on reducing the risk in Asians transiting from being pre-diabetics to diabetics.

\section{Key words: Protein-rich meals: Rice: Blood glucose: Metabolic effects}

Asia has become the epicentre of type 2 diabetes (T2D) ${ }^{(1)}$, predominantly because of the consumption of carbohydraterich and high-glycaemic-index (GI) diets. The consumption of white rice, a major carbohydrate staple in Asian diet, has been linked to rise in T2D in this region ${ }^{(2,3)}$. In addition, Asians have a unique phenotype that makes them more susceptible to diabetes compared with Caucasians ${ }^{(4)}$. Asian populations have a high prevalence of pre-diabetes, impaired fasting glucose, impaired glucose tolerance and a more rapid progression to diabetes ${ }^{(5-7)}$. The transition and severity of pre-diabetes to diabetes is more marked in this population. It has been estimated that, by 2025, the prevalence of T2D will continue to increase from 4 to $5 \cdot 4 \%{ }^{(8)}$.

Although the prevalence of T2D is rising rapidly in Asia and worldwide, making a few lifestyle changes such as eating healthy diets can markedly lower the chances of developing pre-diabetes and diabetes. It is well known that white rice elicits a relatively large glycaemic response (GR) and is thus associated with impaired glucose tolerance ${ }^{(9)}$. On the other hand, there is growing evidence that the consumption of low-GI diets minimises blood glucose excursions, thus helping in the management and prevention of diabetes and pre-diabetes ${ }^{(10)}$. It could therefore be hypothesised that devising simple culinary procedures to reduce the GR of rice is beneficial for those with diabetes and pre-diabetes in Asia. Dietary interventions are the most effective and economical methods in diabetes management and prevention compared with drug-based therapy ${ }^{(11)}$.

There is an increased interest in the use of food ingredients and components such as $\beta$-glucan, galactomannan and isomaltulose to lower GR of carbohydrate-rich foods ${ }^{(12-14)}$. Besides these functional food components, dietary proteins have recently attracted considerable interest, not only because protein is the principle macronutrient involved in all structural units of the body but also because high-protein diets have been shown to be beneficial in affecting blood glucose, blood pressure, heart health and CVD ${ }^{(15,16)}$. Previous studies have shown a reduction in postprandial glucose response when proteins and carbohydrates were co-ingested compared with the uptake of carbohydrates alone in both normal individuals ${ }^{(17)}$ and in patients with $\mathrm{T} 2 \mathrm{D}^{(18,19)}$. However, the metabolic effects of

Abbreviations: BCAA, branched chain amino acids; EAA, essential amino acids; GR, glycaemic response; iAUC, incremental AUC; IR, insulin response; RWE, rice with egg white; RWF, rice with fish; RWT, rice with soya beancurd (taukwa); T2D, type 2 diabetes.

* Corresponding author: C. J. Henry, fax +656776 6840, email jeya_henry@sics.a-star.edu.sg 
proteins when co-ingested with a carbohydrate were found to be conditional upon their quality and quantity, largely because of the differences in their amino acid composition ${ }^{(20,21)}$. It has been demonstrated that amino acids play an important role in insulin secretion and glucose homoeostasis ${ }^{(22)}$. When consumed in combination with carbohydrates, amino acids, including Arg, Pro, Phe, Glu and branched chain amino acids (BCAA), showed greater effects on blood glucose, insulin and glucagon. For example, the consumption of a beverage containing an amino acid mixture, that is, Ile, Leu, Cys, Met and Val, and carbohydrate (100 g dextrose) by healthy overweight subjects significantly increased the plasma glucagon and decreased plasma glucose response compared with the consumption of $100 \mathrm{~g}$ of dextrose. There were no differences in insulin responses (IR) ${ }^{(23)}$. In contrast, the amino acid mixture consisting of Leu, Ile, Val, Lys and Thr resulted in similar glycaemic and insulinaemic responses as whey in another study ${ }^{(24)}$.

Given the high intake of white rice in Asia, the development of methods to reduce the GR is imperative in order to avoid the development of pre-diabetes and diabetes. The notable effects of proteins on insulin secretion and glycaemic control prompted us to explore whether commonly consumed proteins in Asia could lower the GR of white rice. The early work on the influence of proteins on carbohydrates was mostly based on feeding graded amounts of protein in the presence of pure glucose $^{(18,20)}$. Our study, in contrast, uses white rice, a widely consumed carbohydrate staple, to determine the glucoselowering effects of protein in mixed meals, that is, fish, chicken, egg white and soya beancurd. It is generally recognised that Asians consume a composite meal predominantly consisting of rice and at least a protein source and a vegetable. However, the effects of consuming a composite meal comprising protein on postprandial GR cannot be predicted reliably using in vitro studies or predictive models. Thus, the aim of this study was to examine the effects of co-ingesting a protein-rich meal on GR elicited by rice in healthy subjects.

\section{Methods}

\section{Test subjects}

In all, fifteen healthy Chinese male participants were recruited through advertisements and posters that were placed within the National University of Singapore. Potential participants were briefed on all aspects of the study before informed consent was obtained. Upon obtaining informed consent, participants were tasked to complete a health questionnaire in which details of food allergies/intolerance, metabolic diseases, special dietary needs and smoking habits were acquired. Anthropometric measurements were determined and those who fulfilled all the inclusion criteria (age, 21-40 years; BMI, $18.0-24.9 \mathrm{~kg} / \mathrm{m}^{2}$; systolic blood pressure, $110-120 \mathrm{mmHg}$; diastolic blood pressure, 75-85 mmHg; fasting blood glucose, 4-6 mmol/1; no glucose-6phosphate dehydrogenase deficiency; not on any prescription medication that affects glucose-related metabolism; non-smoking; no genetic or metabolic diseases) were included in the study. Physical activity was quantified using the questionnaire of Baecke et $a l^{(25)}$, and only those not participating in competitive and/or endurance sports were included. Before the test day, participants were asked to restrict alcohol and caffeinecontaining drinks, as well as to restrict their participation in intense physical activity.

The study was conducted at the Clinical Nutrition Research Centre (CNRC), Singapore Institute for Clinical Sciences (SICS), Singapore. All participants gave written informed consent before starting, and the study was initiated after ethical approval by the Domain Specific Review Board of National Healthcare Group, Singapore. The study was conducted according to the ethical guidelines founded on the Declaration of Helsinki.

\section{Study protocol}

The study had a randomised, controlled, non-blind, cross-over design in which participants were required to come for five test sessions on non-consecutive days. Standardised dinner was given to the participants to consume the evening before each test day. All test sessions lasted approximately $4 \mathrm{~h}$ and were identical in all aspects except for the test foods consumed. At each test session, participants arrived at CNRC between 08.00 and 09.00 hours following a 10-h overnight fast. An indwelling catheter was inserted into the antecubital fossa upon the participant's arrival and kept patent. Participants had the option to choose whether they would prefer to apply EMLA cream 5\% at least 60 min (self application at home) before insertion of the catheter to prevent any associated pain. Baseline finger-prick (two baseline values taken $5 \mathrm{~min}$ apart) and venous blood samples were collected after the insertion of the catheter. The test meal was consumed within $12 \mathrm{~min}$. During the test sessions, participants were instructed to maintain low physical activity throughout the following $3.5 \mathrm{~h}$ of blood sampling (every $15 \mathrm{~min}$ for the first hour and every $30 \mathrm{~min}$ for the subsequent hours). Working space, free Wi-Fi access and a television were provided for their use. Snacks were given at the end of the test session. Upon completion of all five sessions, they were debriefed and compensated for their time and travel.

\section{Test meals}

Five rice-based test meals (including one control meal with rice only) were served with different protein-rich foods: steamed fish fillet, boiled egg white, soya beancurd (taukwa) and chicken breast. All test meals were given in isoglycaemic proportions of $50 \mathrm{~g}$ of available carbohydrate and $29.5 \mathrm{~g}$ of protein. The control consisting of only rice contained $50 \mathrm{~g}$ of available carbohydrate. The nutrient contents of the test meals were analysed using the Kjeldahl method ${ }^{(26)}$ and Soxhlet method ${ }^{(27)}$ before the start of recruitment of participants (Table 1).

Table 1. Nutrient composition and serving sizes of the test meals

\begin{tabular}{lccccc}
\hline & Rice & RWF & RWT & RWE & RWC \\
\hline Protein (g) & 4.5 & 29.5 & 29.5 & 29.5 & 29.5 \\
Carbohydrates (g) & 50 & 50 & 50 & 50 & 50 \\
Fat (g) & 0.3 & 1.0 & 7.6 & 0.4 & 1.4 \\
Serving quantity (g) & 158.4 & 285.8 & 290.4 & 385.4 & 267.4 \\
\hline
\end{tabular}

RWF, rice with fish; RWT, rice with soya beancurd (taukwa); RWE, rice with egg white; RWC, rice with chicken. 


\section{Preparation and cooking of test meals}

All of the meals were freshly prepared in the morning on test days and served to the participants within $30 \mathrm{~min}$ of preparation.

White rice (Thai Hom Mali Fragrant Rice) was purchased from a local supermarket (FairPrice NTUC). A quantity of $500 \mathrm{ml}$ of water was boiled before $63.6 \mathrm{~g}$ of rice was added. The rice was brought to a boil and was allowed to simmer for $10 \mathrm{~min}$. After cooking, the rice was drained immediately using a sieve and served.

Fresh sea bass (Dicentrarchus labrax) fillet was purchased from a local supermarket (Giant). The fish was filleted and one teaspoon $(5 \mathrm{ml})$ of standard light soya sauce (Tai Hua, FairPrice NTUC) was added. Fish was wrapped in aluminium foil and steamed at $100^{\circ} \mathrm{C}$ for $10 \mathrm{~min}$. Rice was eventually served with the fish (RWF).

Whole eggs (Seng Choon) were purchased from a local supermarket (FairPrice NTUC). In all, eight eggs were boiled at $100^{\circ} \mathrm{C}$ for $15 \mathrm{~min}$. One teaspoon of standard light soya sauce was added to the boiled egg whites. Similarly, rice was served with the egg whites (RWE).

Soya beancurd (taukwa) (Fortune) was purchased from a local supermarket (FairPrice NTUC). Soya beancurd (taukwa) was sliced into approximately $0.5-\mathrm{cm}$ cubes and steamed in a bowl with one teaspoon of standard light soya sauce at $100^{\circ} \mathrm{C}$ for $5 \mathrm{~min}$. Rice was then served with the soya beancurd (taukwa) (RWT).

Fresh chicken breast meat without skin was purchased from a local supermarket (Giant). The chicken was cut into $0.5-\mathrm{cm}$ cubes, and one teaspoon $(5 \mathrm{ml})$ of standard light soya sauce (Tai Hua, FairPrice NTUC) was added. Chicken was wrapped in aluminium foil and steamed at $100^{\circ} \mathrm{C}$ for $10 \mathrm{~min}$ before serving with rice (RWC).

\section{Blood analysis}

Blood was obtained by finger-prick using the Accu-Chek sterile single-use lancing device (Abbott). The first two drops of blood expressed were discarded and the next drop was used for testing. Two finger-prick capillary blood samples were obtained for determining blood glucose concentration using the HemoCue 201+RT Glucose analyzer (HemoCue Ltd). In addition, $3 \mathrm{ml}$ of venous blood was collected into Vacutainers (Becton, Dickinson Diagnostics) containing dipotassium EDTA for insulin analysis. A quantity of $3 \mathrm{ml}$ of venous blood was collected into Vacutainers containing dipotassium EDTA that was added with dipeptidyl peptidase-4 inhibitor (Ile-Pro-Ile; Sigma Aldrich) and protease inhibitor (complete, mini, EDTA-free; Roche) for glucagon analysis. Blood samples were separated by centrifugation at $4500 \mathrm{rpm}$ for $10 \mathrm{~min}$ at $4^{\circ} \mathrm{C}$, and plasma aliquots were stored at $-80^{\circ} \mathrm{C}$ until analysis. Plasma insulin $(\mu \mathrm{IU} / \mathrm{ml})$ was measured using the immunochemistry analyzer COBAS e411 (Roche, HITACHI). Plasma glucagon was analysed using a glucagon EIA kit (RayBiotech).

\section{Data processing and statistical analysis}

The total GR over 120 min was expressed as the incremental AUC (iAUC) using the trapezoidal rule ignoring the area beneath the baseline ${ }^{(28,29)}$. The data were converted to 'the change in GR'. The change in GR was calculated by computing the difference between the blood glucose concentration at a specific time point and mean baseline blood glucose concentration. Similarly, insulin and glucagon data were processed the same way GR data were processed. Statistics were determined by repeated-measures ANOVA, which was Bonferronicorrected for multiple comparisons. Data are presented as mean values with their standard errors.

The BCAA:essential amino acids (EAA) ratios were calculated by taking the ratio of the total BCAA (Val, Leu and Ile) to individual EAA including Met, His, Lys, Thr, Phe and Trp.

All statistical significance was evaluated at an $\alpha$-value of 0.05 .

\section{Results}

\section{Postprandial glycaemic response}

The postprandial blood glucose responses to the different test meals showed different temporal profiles (Fig. 1(a)). Although all test meals induced a glucose response that reached a peak at $30 \mathrm{~min}$ after consumption, the control meal (rice alone) peaked at $45 \mathrm{~min}$ (with incremental blood glucose of $2.56 \mathrm{mmol} / \mathrm{l}$ ). When expressed as iAUC, RWT showed a statistically significant reduction in glucose response over 120 min compared with the control meal $(P<0.05$; Fig. 1(b)). However, no significant differences were observed in the other test meals containing protein sources.
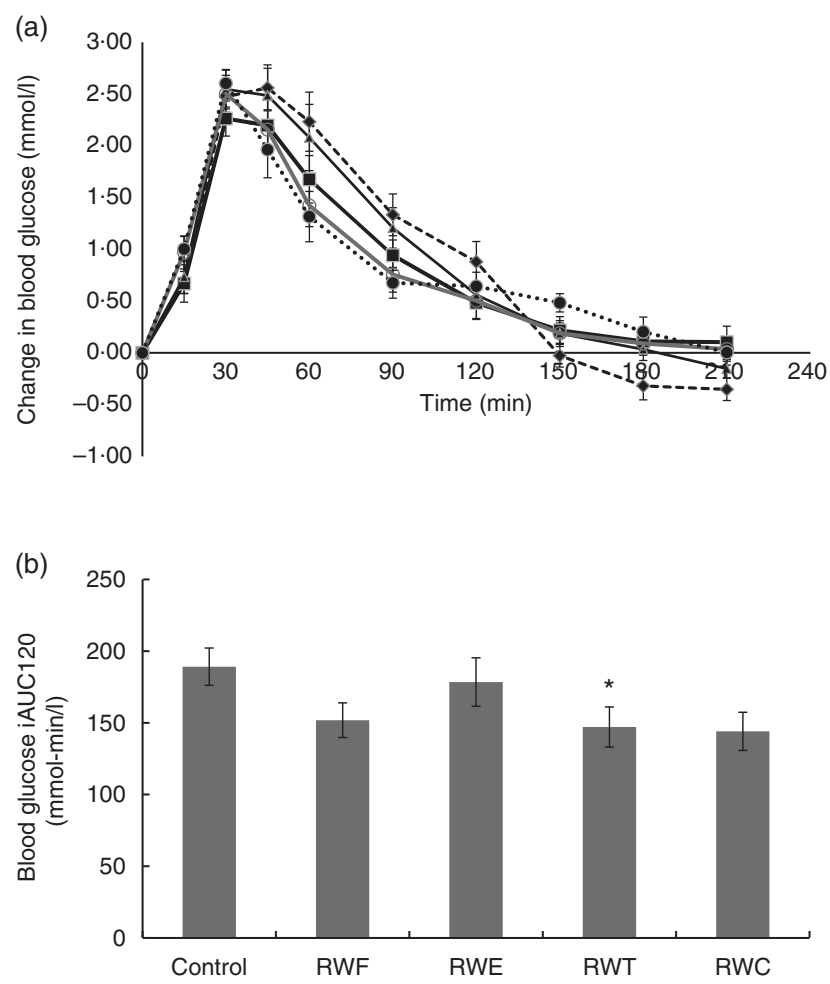

Fig. 1. (a) Changes in plasma glucose of fifteen healthy male volunteers after consumption of five different test meals: rice (Control, --- ), rice with fish (RWF, - - $)$, rice with egg white (RWE, - - ), rice with soya beancurd

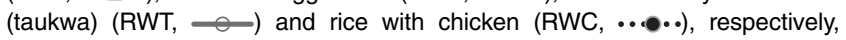
following the standardised dinner. (b) Net incremental AUC (iAUC) using fasting values as baseline. Values are means, with standard errors represented by vertical bars. * Significantly different when compared with control meal using repeated-measures test: $P<0.05$. 


\section{Postprandial plasma insulin}

Fig. 2(a) shows that all test meals and the control meal induced an IR that reached a peak at $30 \mathrm{~min}$ after consumption. The incremental peak IR was highest for RWF $(46 \cdot 1 \mu \mathrm{IU} / \mathrm{ml})$ followed by RWC $(44.7 \mu \mathrm{IU} / \mathrm{ml})$. Interestingly, all the test meals showed a decrease in IR after $30 \mathrm{~min}$, except RWF and RWE, which sustained a longer insulin release between 30 and $60 \mathrm{~min}$ before decreasing. The control meal had the lowest incremental peak $(33.9 \mu \mathrm{IU} / \mathrm{ml})$ and it showed the lowest rate of insulin released compared with test meals that contained protein sources. Expressed as iAUC, both RWF and RWE demonstrated statistically significant increases in IR compared with the control meal $(P<0.02)$. In contrast, there was no significant difference in the iAUC for RWT $(2860 \cdot 6 \mu \mathrm{IU} / \mathrm{ml})$ compared with rice control (2606.5 $\mu \mathrm{IU} / \mathrm{ml})$ (Fig. 2(b)).

\section{Postprandial plasma glucagon}

The plasma glucagon concentration after consuming the control meal was suppressed to a level beneath the baseline throughout the postprandial period, except at 90 and $120 \mathrm{~min}$ (Fig. 3(a)). However, all test meals based on $25 \mathrm{~g}$ of protein resulted in a marked increase in glucagon concentrations. Expressing the
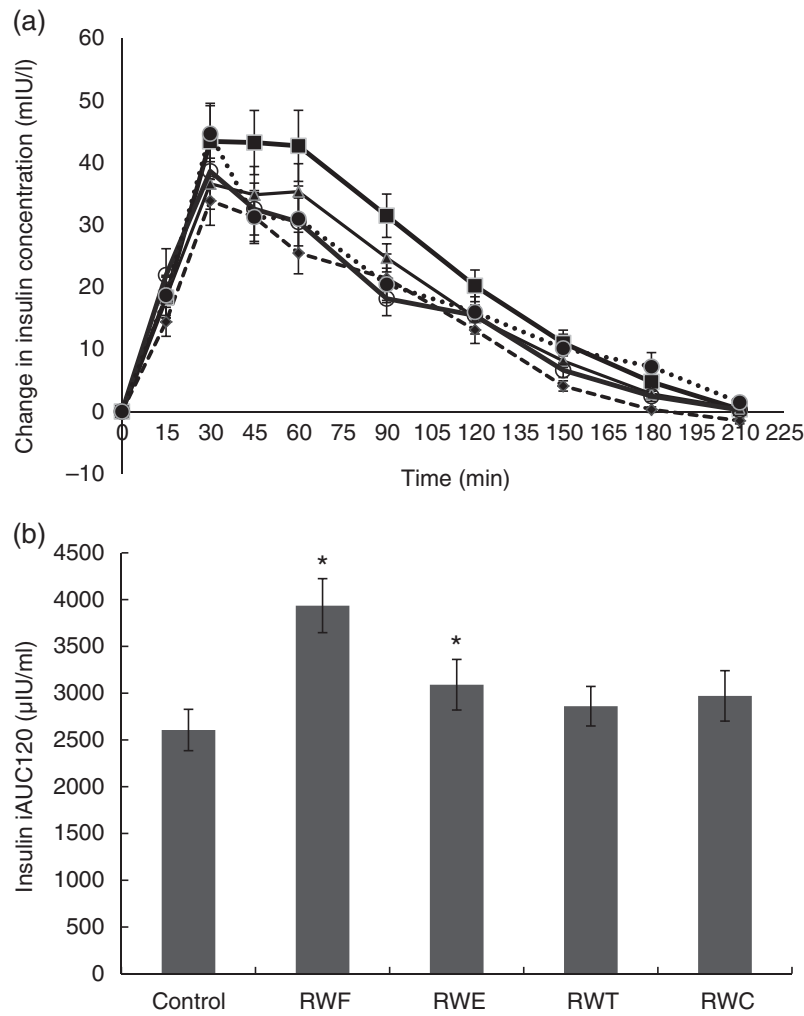

Fig. 2. (a) Changes in plasma insulin of fifteen healthy male volunteers after consumption of five different test meals: rice (Control, - - - ), rice with fish (RWF, - - - ), rice with egg white (RWE, - - ), rice with soya beancurd (taukwa) (RWT, - ) and rice with chicken (RWC, ..••), respectively, following the standardised dinner. (b) Net incremental AUC (iAUC) using fasting values as baseline. Values are means, with standard errors represented by vertical bars. * Significantly different when compared with control meal using repeated-measures test: $P<0.05$. result as an iAUC, the plasma glucagon concentration after RWF $(P=0.023)$ and RWT $(P=0.007)$ was significantly higher when compared with the control meal (Fig. 3(b)). It should be noted that the glucagon concentrations reached its peak at varied time points for RWF (90 min) and RWT $(30 \mathrm{~min})$, although the maximum glucagon increments for RWF (14.7 ng/l) and RWT (15.0 ng/l) were similar.

\section{Amino acid profiles}

In all, eighteen amino acids were detected and identified, as shown in Table 2. The ratio of BCAA:individual EAA, such as Met, His, Lys, Thr, Phe and Trp, was also evaluated for all protein sources. As compared with the animal protein sources, that is, fish, egg white and chicken, soya beancurd (taukwa) had the lowest content of BCAA and EAA levels. However, soya beancurd (taukwa) had a notably much higher BCAA:Met ratio compared with chicken, fish and egg white (Table 2). A regression analysis (Spearman's $\rho$ ) was carried out between the ratio of BCAA:EAA with GR. Table 3 shows that an increase in BCAA:Met ratio was significantly associated with a decrease in GR $(P=0 \cdot 004)$. However, no statistical association was observed for GR with the ratios of BCAA:His, Lys, Thr, Phe and Trp, respectively.
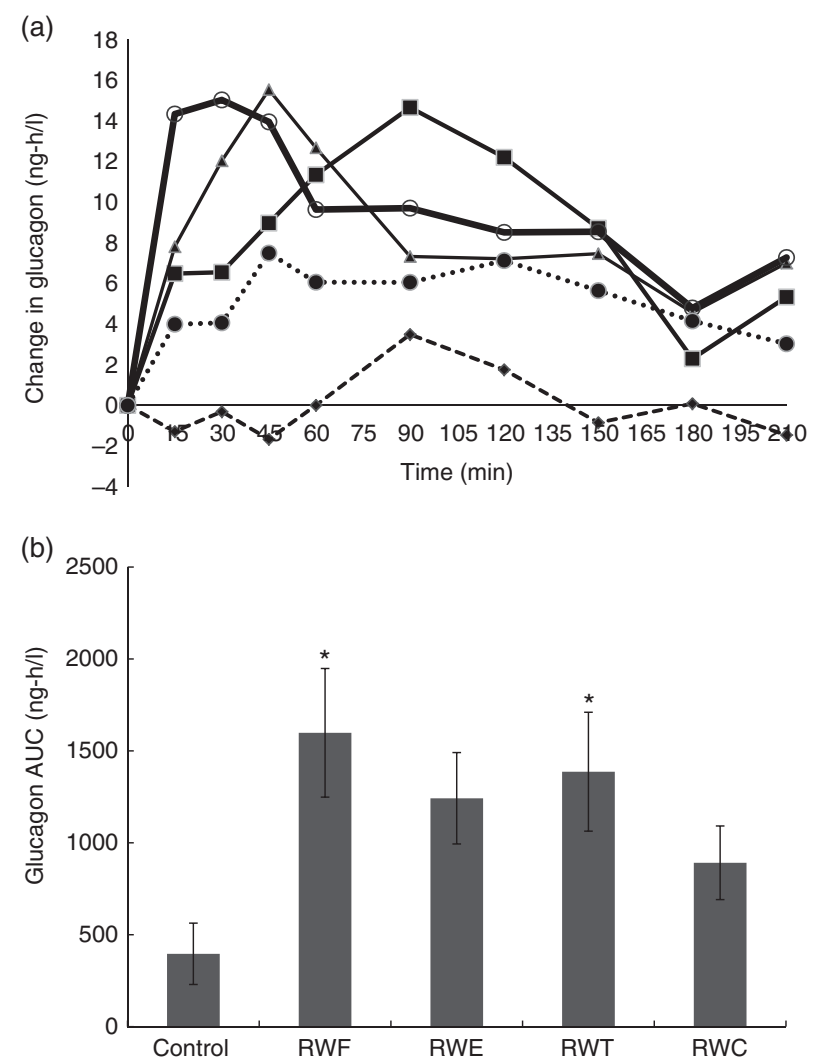

Fig. 3. (a) Changes in plasma glucagon of fifteen healthy male volunteers after consumption of five different test meals: rice (Control, $-\rightarrow-$ ), rice with fish (RWF, - (taukwa) (RWT, —) and rice with chicken (RWC, $\cdots \bullet \bullet$ ), respectively, following the standardised dinner. (b) Net incremental AUC (iAUC) using fasting values as baseline. Values are means, with standard errors represented by vertical bars. * Significantly different when compared with control meal using repeated-measures test: $P<0.05$. 
Table 2. Amino acid levels in different protein sources

\begin{tabular}{|c|c|c|c|c|}
\hline $\begin{array}{l}\text { Amino acids } \\
(\mathrm{mg} / 100 \mathrm{~g})\end{array}$ & Fish & Egg white & $\begin{array}{c}\text { Soya } \\
\text { beancurd (taukwa) }\end{array}$ & $\begin{array}{l}\text { Chicken } \\
\text { breast }\end{array}$ \\
\hline Asp & 2250 & 1490 & 1520 & 2160 \\
\hline Thr & 989 & 640 & 493 & 1030 \\
\hline Ser & 860 & 968 & 676 & 886 \\
\hline Glu & 3350 & 1890 & 2440 & 3370 \\
\hline Pro & 784 & 502 & 690 & 860 \\
\hline Gly & 999 & 469 & 504 & 955 \\
\hline Ala & 1280 & 864 & 564 & 1360 \\
\hline Val & 1050 & 948 & 642 & 1180 \\
\hline Ile & 1030 & 787 & 637 & 1150 \\
\hline Leu & 1710 & 1200 & 1040 & 1820 \\
\hline Tyr & 777 & 572 & 519 & 806 \\
\hline Phe & 887 & 865 & 711 & 914 \\
\hline Lys & 1940 & 862 & 754 & 1950 \\
\hline His & 456 & 305 & 317 & 720 \\
\hline Arg & 1400 & 1050 & 1030 & 1870 \\
\hline Cys & 217 & 407 & 191 & 229 \\
\hline Met & 677 & 557 & 198 & 688 \\
\hline Trp & 198 & 207 & 168 & 290 \\
\hline BCAA & 3790 & 2935 & 2319 & 4150 \\
\hline EAA & 8937 & 6371 & 4960 & 9742 \\
\hline TAA & 20900 & 14600 & 13100 & 22200 \\
\hline BCAA:Met & 5.60 & $5 \cdot 27$ & 11.71 & 6.03 \\
\hline BCAA:His & $8 \cdot 31$ & 9.62 & $7 \cdot 32$ & $5 \cdot 76$ \\
\hline BCAA:Lys & 1.95 & 3.40 & 3.08 & $2 \cdot 13$ \\
\hline BCAA:Thr & 3.83 & 4.59 & $4 \cdot 70$ & 4.03 \\
\hline BCAA:Phe & $4 \cdot 27$ & 3.39 & 3.26 & 4.54 \\
\hline BCAA:Trp & $19 \cdot 14$ & $14 \cdot 18$ & $13 \cdot 80$ & $14 \cdot 31$ \\
\hline
\end{tabular}
amino acids.

\section{Discussion}

The present study shows a promising effect of co-ingesting a carbohydrate source with a protein-rich meal in reducing postprandial blood glucose response. Proteins have previously been shown to stimulate insulin secretion and reduce $\mathrm{GR}^{(18,19,30,31)}$. Our study demonstrates that all protein-rich meals are not equivalent in the way they affect glucose homoeostasis. As proteins have differing amino acid composition, these appear to affect blood glucose regulations, insulin and glucagon secretion.

The addition of soya protein beancurd to white rice (RWT) showed a significant reduction in blood glucose response when compared with consuming rice on its own (control meal). The benefits of soya protein on blood glucose have previously been reported with most studies conducted in diabetics ${ }^{(32,33)}$. To the best of our knowledge, this is the first study to show that when a soya protein food (i.e. soya beancurd (taukwa)) was consumed with rice, a lowering of the blood glucose response was observed in healthy individuals. Moreover, unlike RWF and RWE, which significantly increased postprandial IR, RWT did not result in a significant rise in IR, which is consistent with previous studies ${ }^{(34,35)}$. These results, when combined, suggest that co-ingestion of soya protein with carbohydrate markedly attenuates the postprandial GR without a change in IR. However, consumption of RWT significantly increased plasma glucagon response. It is likely that certain amino acids present in soya protein may have little effect on insulin secretion but stimulate glucagon $^{(36)}$. Although a previous study showed that
Table 3. Spearman's correlation coefficients and $P$ values for the relations between branched chain amino acids (BCAA):essential amino acids ratio and glycaemic response of different test meals

\begin{tabular}{lrrrrrr}
\hline & $\begin{array}{c}\text { BCAA: } \\
\text { Met }\end{array}$ & \multicolumn{1}{c}{$\begin{array}{c}\text { BCAA: } \\
\text { His }\end{array}$} & $\begin{array}{c}\text { BCAA: } \\
\text { Lys }\end{array}$ & $\begin{array}{c}\text { BCAA: } \\
\text { Thr }\end{array}$ & \multicolumn{1}{c}{$\begin{array}{c}\text { BCAA: } \\
\text { Phe }\end{array}$} & \multicolumn{1}{c}{$\begin{array}{c}\text { BCAA: } \\
\text { Trp }\end{array}$} \\
\hline iAUC & -0.330 & -0.039 & -0.088 & -0.182 & -0.195 & -0.176 \\
$P$ & 0.004 & 0.738 & 0.455 & 0.118 & 0.093 & 0.130 \\
\hline
\end{tabular}

iAUC, net incremental AUC.

soya protein given in combination with Lys increased total insulin secretions ${ }^{(37)}$, we found that soya protein showed the lowest Lys content compared with the other protein foods (Table 2). Although soya protein contained low levels of Lys, Gly and Phe, which are known as glucogonogenic ${ }^{(36)}$, the consumption of RWT in the present study showed an increase in glucagon secretion, which is required to raise blood glucose level and prevent hypoglycaemia ${ }^{(38)}$. A study conducted by Claessens et al. ${ }^{(34)}$ also showed the same trend, where there was a significant reduction in GR and an increase in glucagon response despite not having an increase in insulin secretion.

Soyabean, as a member of the legume family, is a rich source of protein, fibre, vitamins, minerals, fat, isoflavones and phytooestrogens that may affect glycaemic control and lipid profile $^{(39)}$. There is evidence to suggest that, besides protein, fat and isoflavones in soyabeans may also have glucose-lowering effects. Although the two major metabolically active isoflavones, namely genistein and daidzein, are generally present in soya $^{(40)}$, the amounts are minute (online Supplementary Table S1) ${ }^{(41)}$. Moreover, several studies have shown statistically significant associations of both genistein and daidzein in glycaemia amongst women but not in men ${ }^{(42,43)}$. As the present study comprised only males, it implies that the presence of isoflavones in soya protein would be an unlikely confounding factor that may have reduced blood glucose levels. We, however, hypothesise that the significant glucose reduction in RWT was partly attributed to the high fat content $(7.6 \mathrm{~g})$, as shown in Table 1. Previous studies suggest that across a range of $0-30 \mathrm{~g}$ of protein and fat, both components reduced the GR of glucose. However, protein had a two to three times greater effect than fat $^{(44)}$. Therefore, we surmise that the glucose-lowering effects of fat in RWT should be modest compared with the effects of protein, which was four times the fat content. Further investigation of the effects of fat on GR is ongoing in our laboratory.

In the present study, the test meals of RWE and RWF resulted in a significant increase in insulin secretion. Previously, Gannon et $a .^{(18)}$ showed that consuming fish with a carbohydrate source (glucose) produced one of the highest IR compared with other protein foods. On the other hand, in another study, egg white consumed with glucose had the lowest IR, where it was estimated that $47 \%$ of egg white protein was metabolised compared with $70 \%$ of cottage cheese protein ${ }^{(45)}$. IR has also been shown to be related to protein digestion rate ${ }^{(46)}$. We found that the consumption of RWF resulted in significantly high glucagon secretion. This is probably because amino acids present in fish protein have a direct or synergistic effect on glucagon secretion. Kuhara et $a l^{(47)}$ assessed the metabolic 
response to seventeen individual amino acids and found that all the amino acids potentiating glucagon release also stimulated insulin. In our study, we have demonstrated that the consumption of a protein meal stimulates glucagon secretion with RWF and RWT both showing a statistically significant increase in glucagon concentration $(P<0.05)$. This is in agreement with RWT having the lowest blood glucose response (Fig. 1). An increase in glucagon secretion is necessary to raise the blood glucose level to prevent hypoglycaemia ${ }^{(38)}$. This implies that the consumption of protein such as soya beancurd (taukwa) attenuates the effect of glucagon.

Although BCAA are known to influence insulin and $\mathrm{GR}^{(48)}$, it is impossible to describe which precise amino acid in soya protein is influencing glycaemic reduction. It is interesting to note that soya proteins compared with all other types of protein are deficient in $\mathrm{Met}^{(49)}$. We evaluated the ratio of BCAA:EAA to its relationship with GR (Table 3). Results have shown that a change in BCAA:Met is statistically associated with a change in GR; that is, increase intake in BCAA:Met is associated with a reduction in GR. In contrast, the association between the ratio of BCAA:His, Lys, Thr, Phe and Trp and the change in GR is absent (Table 3 ). It appears that soya beancurd (taukwa) has an optimum amino acid ratio in reducing GR.

Although Layman ${ }^{(50)}$ reported that Leu, a BCAA found mostly in soya beancurd (taukwa), chicken and fish, was involved in the critical metabolic processes, the more important factor that influenced the nutritional value of a protein source was the relative content and metabolic availability of an individual EAA. Without the correct proportions of the EAA in the diet, the utilisation of other amino acids will be limited, thus preventing normal rates of protein synthesis despite the adequate total $\mathrm{N}$ intake level ${ }^{(50)}$. It was also shown that soya protein supported $\mathrm{N}$ balance and is on par with beef and milk protein ${ }^{(51)}$. Cell culture studies demonstrated that Leu promotes glucose uptake independent of the insulin signalling pathway; in other words, amino acids activate mechanistic target of rapamycin (mTOR) for glucose uptake in the absence of insulin ${ }^{(52,53)}$. Human studies have shown that feeding high proportions of BCAA with glucose promotes activation of $\mathrm{mTOR}^{(54,55)}$. This implies the possibility that amino acids promote glucose uptake synergistically with insulin. The effect was demonstrated in our study with soya beancurd (taukwa) as an example.

Our study demonstrated that there is a hierarchy of effect on glucose reduction between the test protein-based meals. Protein source appears to partly determine the nature of the metabolic response presumably because of differences in amino acid composition ${ }^{(56,57)}$. RWT had the best effect followed by RWC, RWF and RWE sequentially. The substantial reduction in postprandial glycaemia observed with RWT was comparable to what was observed with the addition of pharmacological therapies such as metformin and sulphonylurea ${ }^{(58)}$. This observation was also consistent with epidemiological studies in which the consumption of unsweetened soya products is inversely associated with the risk of T2D; however, the effects were not observed in meat proteins ${ }^{(33,59)}$.

In Asia, soya is consumed in various forms, namely soya beancurd (taukwa; firm tofu), silken tofu (soft), beancurd skin (foo pei), tau pok, tau huay, soyabean drink, etc. ${ }^{(33)}$. According to the Shanghai Women's Health Study, there was an observable protective effect of T2D when there was a small increase of soyabean intake from $2 \cdot 8$ to $6.8 \mathrm{~g} / \mathrm{d}^{(60)}$. On average, it was reported that soyabean intake was $11 \cdot 0 \mathrm{~g} / \mathrm{d}^{(60)}$. We can infer from this that long-term consumption of soyabean products is achievable and will be beneficial in the management of T2D.

\section{Conclusion}

Co-ingestion of soya protein beancurd together with rice is capable of reducing blood glucose. However, there is a hierarchy of protein meal effect on GR. Of particular interest is the finding for the first time that the inclusion of soya protein beancurd, that is, RWT, induced a significant effect on blood glucose reduction. Given that soya protein-based foods are extensively and widely consumed in the form of soya beancurd, soya milk and beancurd skin in Asia, their inclusion in the diet would be highly desirable $^{(33)}$. These results suggest that it may be possible to tailor low GR to rice meals with the inclusion of soya beancurd (taukwa). This dietary advocacy may facilitate glycaemic regulation and be useful in managing T2D in populations that consume a diet rich in rice. The inclusion of soya protein appears to be a simple, acceptable and palatable means of reducing the GR of rice. Rice-based diets are popular in Asia. The observation presented may have a direct impact on reducing the risk in Asians transiting from pre-diabetics to diabetics.

\section{Acknowledgements}

The authors thank Lim Zhi'En Joseph for his support on statistical analysis.

The authors are grateful to the SICS for funding the study.

C. J. H. contributed to the conception and the design of the study. R. Q. carried out the study, analysis of glucose and insulin blood samples and statistical analysis of data. X. B. carried out analysis of glucagon blood samples. R. Q., X. B. and C. J. H. drafted the manuscript. All authors critically reviewed the contents of the manuscript and approved the final version of the manuscript.

None of the authors has any conflicts of interest to declare.

\section{Supplementary material}

For supplementary material/s referred to in this article, please visit http://dx.doi.org/doi:10.1017/S0007114515005498

\section{References}

1. Yoon KH, Lee JH, Kim JW, et al. (2006) Epidemic obesity and type 2 diabetes in Asia. Lancet 368, 1681-1688.

2. Fitzgerald MA, McCouch SR \& Hall RD (2009) Not just a grain of rice: the quest for quality. Trends Plant Sci 14, 133-139.

3. Hu EA, Pan A, Malik V, et al. (2012) White rice consumption and risk of type 2 diabetes: meta-analysis and systematic review. BMJ 344, e1454.

4. Hu FB (2011) Globalization of diabetes:the role of diet, lifestyle, and genes. Diabetes Care 34, 1249-1257.

5. Katulanda P, Constantine GR, Mahesh JG, et al. (2008) Prevalence and projections of diabetes and pre-diabetes in 
adults in Sri Lanka - Sri Lanka Diabetes, Cardiovascular Study (SLDCS). Diabet Med 25, 1062-1069.

6. Wen CP, Cheng TYD, Tsai SP, et al. (2005) Increased mortality risks of pre-diabetes (impaired fasting glucose) in Taiwan. Diabetes Care 28, 2756-2761.

7. Yang W, Lu J, Weng J, et al. (2010) Prevalence of diabetes among men and women in China. N Engl J Med 362, 1090-1101.

8. Fall CHD (2001) Non-industrialised countries and affluence relationship with type 2 diabetes. Br Med Bull 60, 33-50.

9. Sun Q, Spiegelman D, van Dam RM, et al. (2010) White rice, brown rice, and risk of type 2 diabetes in US men and women. Arch Intern Med 170, 961-969.

10. Foster-Powell K, Holt SHA \& Brand-Miller JC (2002) International table of glycemic index and glycemic load values: 2002. Am J Clin Nutr 76, 5-56.

11. Kelley DE (2003) Sugars and starch in the nutritional management of diabetes mellitus. Am J Clin Nutr 78, 858S-864S.

12. Cavallero A, Empilli S, Brighenti F, et al. (2002) High $(1 \rightarrow 3$, $1 \rightarrow 4)$ - $\beta$-glucan barley fractions in bread making and their effects on human glycemic response. J Cereal Sci 36, 59-66.

13. Jenkins AL, Jenkins DJ, Zdravkovic U, et al. (2002) Depression of the glycemic index by high levels of beta-glucan fiber in two functional foods tested in type 2 diabetes. Eur J Clin Nutr 56, 622-628.

14. Sharma RD (1986) Effect of fenugreek seeds and leaves on blood glucose and serum insulin responses in human subjects. Nutr Res 6, 1353-1364.

15. Appel LJ (2003) The effects of protein intake on blood pressure and cardiovascular disease. Curr Opin Lipidol 14, 55-59.

16. Erdman JW (2000) Soy protein and cardiovascular disease: a statement for healthcare professionals from the Nutrition Committee of the AHA. Circulation 102, 2555-2559.

17. Krezowski PA, Nuttall FQ, Gannon MC, et al. (1986) The effect of protein ingestion on the metabolic response to oral glucose in normal individuals. Am J Clin Nutr 44, 847-856.

18. Gannon MC, Nuttall FQ, Neil BJ, et al. (1988) The insulin and glucose responses to meals of glucose plus various proteins in type II diabetic subjects. Metabolism 37, 1081-1088.

19. Nuttall FQ, Mooradian AD, Gannon MC, et al. (1984) Effect of protein ingestion on the glucose and insulin response to a standardized oral glucose load. Diabetes Care 7, 465-470.

20. Gannon MC, Nuttall FQ, Lane JT, et al. (1992) Metabolic response to cottage cheese or egg white protein, with or without glucose, in type II diabetic subjects. Metabolism $\mathbf{4 1}$, $1137-1145$.

21. Nuttall FQ \& Gannon MC (2004) Metabolic response of people with type 2 diabetes to a high protein diet. Nutr Metab (Lond) 1, 6.

22. Newsholme P, Brennan L, Rubi B, et al. (2005) New insights into amino acid metabolism, beta-cell function and diabetes. Clin Sci (Lond) 108, 185-194.

23. Wang B, Kammer LM, Ding Z, et al. (2012) Amino acid mixture acutely improves the glucose tolerance of healthy overweight adults. Nutr Res 32, 30-38.

24. Nilsson M, Holst JJ \& Bjorck IME (2007) Metabolic effects of amino acid mixtures and whey protein in healthy subjects: studies using glucose-equivalent drinks. Am J Clin Nutr 85 , 996-1004

25. Baecke JA, Burema J \& Frijters JE (1982) A short questionnaire for the measurement of habitual physical activity in epidemiological studies. Am J Clin Nutr 36, 936-942.

26. Chang SKC (2010) Protein analysis. In Food Analysis, pp. 133-146 [SS Nielsen, editor]. New York: Springer.

27. David B \& Min WCE (2010) Fat analysis. In Food Analysis, 4th ed. pp. 119-132 [SS Nielsen, editor]. New York: Springer Science + Business Media.
28. Allison DB, Paultre F, Maggio C, et al. (1995) The use of areas under curves in diabetes research. Diabetes Care 18, 245-250.

29. Brouns F, Bjorck I, Frayn KN, et al. (2005) Glycaemic index methodology. Nutr Res Rev 18, 145-171.

30. Gannon MC, Nuttall JA \& Nuttall FQ (2002) The metabolic response to ingested glycine. Am J Clin Nutr 76, 1302-1307.

31. Nuttall FQ, Gannon MC \& Jordan K (2004) The metabolic response to ingestion of proline with and without glucose. Metabolism 53, 241-246.

32. Odegaard AO, Koh WP, Butler LM, et al. (2011) Dietary patterns and incident type 2 diabetes in Chinese men and women: the Singapore Chinese health study. Diabetes Care 34, 880-885.

33. Mueller NT, Odegaard AO, Gross MD, et al. (2012) Soy intake and risk of type 2 diabetes in Chinese Singaporeans. Eur J Nutr 51, 1033-1040.

34. Claessens M, Calame W, Siemensma AD, et al. (2009) The effect of different protein hydrolysate/carbohydrate mixtures on postprandial glucagon and insulin responses in healthy subjects. Eur J Clin Nutr 63, 48-56.

35. Moghaddam AS, Entezari MH, Iraj B, et al. (2014) The effects of consumption of bread fortified with soy bean flour on metabolic profile in type 2 diabetic women: a cross-over randomized controlled clinical trial. Int J Prev Med 5 , $1529-1536$

36. Gannon MC \& Nuttall FQ (2010) Amino acid ingestion and glucose metabolism - a review. IUBMB Life 62, 660-668.

37. Sugano M, Ishiwaki N, Nagata Y, et al. (1982) Effects of arginine and lysine addition to casein and soya-bean protein on serum lipids, apolipoproteins, insulin and glucagon in rats. Br J Nutr 48, 211-221.

38. Jiang G \& Zhang BB (2003) Glucagon and regulation of glucose metabolism. Am J Physiol Endocrinol Metab 284, E671-E678.

39. Yang B, Chen Y, Xu T, et al. (2011) Systematic review and meta-analysis of soy products consumption in patients with type 2 diabetes mellitus. Asia Pac J Clin Nutr 20, 593-602.

40. Rekha CR \& Vijayalakshmi G (2010) Influence of natural coagulants on isoflavones and antioxidant activity of tofu. J Food Sci Technol 47, 387-393.

41. Liu J, Chang SKC \& Wiesenborn D (2005) Antioxidant properties of soybean isoflavone extract and tofu in vitro and in vivo. J Agric Food Chem 53, 2333-2340.

42. Ko KP, Kim CS, Ahn Y, et al. (2015) Plasma isoflavone concentration is associated with decreased risk of type 2 diabetes in Korean women but not men: results from the Korean Genome and Epidemiology Study. Diabetologia 58, 726-735.

43. Koh WP, Wu AH, Wang R, et al. (2009) Gender-specific associations between soy and risk of hip fracture in the Singapore Chinese Health Study. Am J Epidemiol 170, 901-909.

44. Moghaddam E, Vogt JA \& Wolever TMS (2006) The effects of fat and protein on glycemic responses in nondiabetic humans vary with waist circumference, fasting plasma insulin, and dietary fiber intake. J Nutr 136, 2506-2511.

45. Nuttall FQ \& Gannon MC (1990) Metabolic response to egg white and cottage cheese protein in normal subjects. Metabolism 39, 749-755.

46. Gannon MC, Nuttall JA, Damberg G, et al. (2001) Effect of protein ingestion on the glucose appearance rate in people with type 2 diabetes. J Clin Endocrinol Metab 86, 1040-1047.

47. Kuhara T, Ikeda S, Ohneda A, et al. (1991) Effects of intravenous infusion of 17 amino acids on the secretion of $\mathrm{GH}$, glucagon, and insulin in sheep. Am J Physiol Endocrinol Metab 260, E21-E26. 
48. Calbet JAL \& MacLean DA (2002) Plasma glucagon and insulin responses depend on the rate of appearance of amino acids after ingestion of different protein solutions in humans. J Nutr 132, 2174-2182.

49. Friedman M \& Brandon DL (2001) Nutritional and health benefits of soy proteins. J Agric Food Chem 49, 1069-1086.

50. Layman DK (2003) The role of leucine in weight loss diets and glucose homeostasis. J Nutr 133, 261S-267S.

51. Food and Nutrition Board (2005) Dietary Reference Intakes for Energy, Carbohydrate, Fiber, Fat, Fatty Acids, Cholesterol, Protein, and Amino Acids (Macronutrients). Washington, DC: The National Academies Press.

52. Bernard JR, Liao Y-H, Doerner PG, et al. (2012) An amino acid mixture is essential to optimize insulin-stimulated glucose uptake and GLUT4 translocation in perfused rodent hindlimb muscle. J Appl Physiol (1985) 113, 97-104.

53. Liu H, Liu R, Xiong Y, et al. (2014) Leucine facilitates the insulin-stimulated glucose uptake and insulin signaling in skeletal muscle cells: involving mTORC1 and mTORC2. Amino Acids 46, 1971-1979.

54. Dreyer HC, Drummond MJ, Pennings B, et al. (2008) Leucineenriched essential amino acid and carbohydrate ingestion following resistance exercise enhances mTOR signaling and protein synthesis in human muscle. Am J Physiol Endocrinol Metab 294, E392-E400.

55. Fujita S, Dreyer HC, Drummond MJ, et al. (2007) Nutrient signalling in the regulation of human muscle protein synthesis. J Physiol 582, 813-823.

56. Pal S \& Ellis V (2010) The acute effects of four protein meals on insulin, glucose, appetite and energy intake in lean men. Br J Nutr 104, 1241-1248.

57. Uhe AM, Collier GR \& O'Dea K (1992) A comparison of the effects of beef, chicken and fish protein on satiety and amino acid profiles in lean male subjects. $J$ Nutr 122, 467-472.

58. Turner RC, Cull CA, Frighi V, et al. (1999) Glycemic control with diet, sulfonylurea, metformin, or insulin in patients with type 2 diabetes mellitus: progressive requirement for multiple therapies (UKPDS 49). JAMA 281, 2005-2012.

59. Sluijs I, Beulens JWJ, Spijkerman AMW, et al. (2010) Dietary intake of total, animal, and vegetable protein and risk of type 2 diabetes in the European Prospective Investigation into Cancer and Nutrition (EPIC)-NL study. Diabetes Care 33, 43-48.

60. Villegas R, Gao YT, Yang G, et al. (2008) Legume and soy food intake and the incidence of type 2 diabetes in the Shanghai Women's Health Study. Am J Clin Nutr 87, 162-167. 